\title{
The Application of EIQ Analysis to The Order Picking of Book Industry
}

\author{
Shan Lu \\ School of Automation \\ Beijing University of Posts and Telecommunications \\ Beijing, China \\ E-mail: shanlu334@aliyun.com \\ Hongyue $\mathrm{Li}^{*}$ \\ School of Automation \\ Beijing University of Posts and Telecommunications \\ Beijing, China \\ E-mail: lhy2101@163.com \\ * Corresponding Author
}

\author{
Xiaojun $\mathrm{Yu}$ \\ Putian Logistics Technology Limited \\ Beijing, China \\ E-mail: xiaojun02yu@sina.com
}

\begin{abstract}
EIQ analysis is based on the order data for logistics planning and has a guiding significance to the selection of order strategy. This article describes the steps and methods of EIQ analysis, combined $\mathrm{ABC}$ classification of book enterprise orders to carry on the EQ, EN, IQ and IK analysis. According to EQ, EN, IQ and IK analysis, entries and items are divided into Class $\mathbf{A}$, Class $B$ and Class $\mathbf{C}$. Class $A$ orders as priority orders should be used in batches picking; Class B orders should be used in general picking; Class $C$ orders as non-priority orders on the basis of artificial picking orders can be combined and use wave picking strategy. Meanwhile, Class $A$ items which are priority items can be placed in easy picking and exit from the position near or easy job to shorten the distance picking; Class $C$ items should be placed on top of the storage area and placed in a position which is far from the exit; Class $B$ items can be placed in the remaining positions. By the EIQ analysis results can understand order demand characteristics and provide data support for reservoir area layout, has chosen the equipment selection, strategy planning.
\end{abstract}

Keywords-EIQ analysis; order; ABC classification; book industry; picking

\section{INTRODUCTION}

With the continuous deepening of reform and the growing cultural needs, the book industry has made considerable progress. Because of the rapid development of the book industry, the level of logistics operations has higher requirements. Book logistics operations includes purchase, storage, sorting, shipping, distribution, etc., sorting operation consumes the most resources. How to determine the reasonable and effective picking strategy according to the order data is the main problem for the book enterprises. EIQ analysis is an effective method for analyzing the logistics characteristic based on the item and quantity of the orders and has guiding significance for the chosen strategy [1].

The layout of this paper is as follows. In the second section, the basic concept of EIQ analysis is simply made.
The third part describes the steps of the implementation of EIQ analysis, and each step makes specific instructions. In the fourth part, the order data of book enterprise are analyzed practical applications, according to the EIQ analysis results to understand demand characteristics, select the appropriate picking strategy. The fifth part summarizes the whole article.

\section{EIQ ANALYSIS}

EIQ analysis is created by Japan authority logistics experts Suzuki shin, according to the order items and quantity for logistics planning. The so-called EIQ refers to entry, item and quantity.

E refers to every order received by the logistics center. Entry specific needs in the same period are picking, and distribution to the same place at the same time features. That is, as long as the order deadline, a few strokes of additional orders can be combined into a single order, the logistics operation process regarded as the same order; otherwise, the same batch of orders requires different times or different locations and distribution, to logistics centers with multiple orders deemed necessary for order split. These two cases occur frequently in real operation.

I mean commodity items or categories. As long as different quality, quantity, packaging unit, and other forms of packaging products, are treated as different items, in principle, to encode the logistics center as case basis. In actual operation should be noted that the coding, maintenance and unification of the commodity.

$Q$ refers to the number of ordered data, which is the bridge between the entry and the item, and analyzes the quantity distribution of the entries and the items can exhibit characteristics of customer demand.

EIQ analysis method is to use E, I, Q cross analysis of the three logistics elements lead to EQ, EN, IQ and IK analysis. EIQ analysis results can understand the characteristics of the order data, so that different customers and different items take different picking strategy [2-3]. 


\section{APPLICATION STEPS OF EIQ ANALYSIS} Fig .1.

The application steps of EIQ analysis [4-5] is shown in

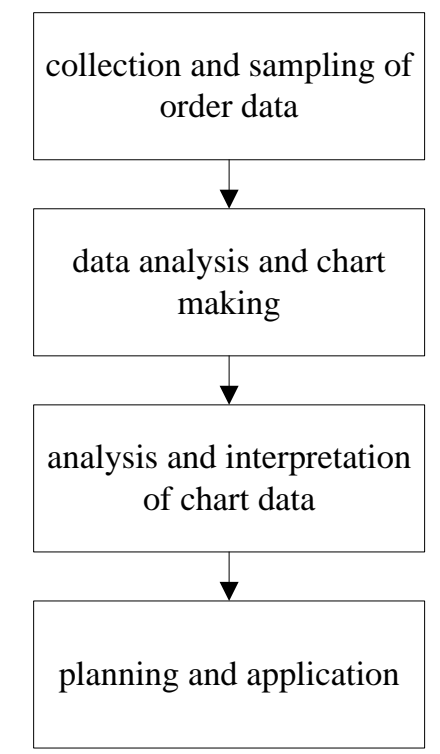

Figure 1. EIQ analysis Implement steps

Collection and sampling of order data: EIQ analysis data can select day, week, month or even quarter as the time range according to the commodity characteristics and operation cycle. This time range should be representative and can reflect the order characteristic. Since the book industry shipments daily fluctuation is bigger, it is difficult to select a representative day. Order data can be compared to select the appropriate time range [6].

Data analysis and chart making: using statistical method to EQ, EN, IQ and IK analysis, and charting the analysis results.

Analysis and interpretation of chart data: use EQ analysis to understand each order's shipment quantity and quantitative distribution, and to determine the important orders and the corresponding picking strategy; Use EN analysis to master each order's shipment items, and to determine the appropriate picking method; the use of IQ analysis to understand single item's shipment quantity and determine inventory levels and processing methods of different items; the use of IK analysis to master commodity shipment frequency and determine regular items, and also can cooperate with IQ analysis to determine the selection of the picking strategy[7].

Planning and application: The choice of order picking strategy based on analysis results.

\section{PRACTICAL APPLICATION OF EIQ ANALYSIS}

Taking a week's order data of a book enterprise as an example, using EIQ analysis to analyze the order data and plan the picking strategy. Specific order data is shown in Table I.

TABLE I. ORDER DATA FOR BOOK ENTERPRISE

\begin{tabular}{|c|c|c|c|c|c|c|c|c|c|c|c|c|c|c|}
\hline \multirow{2}{*}{ Entry } & \multicolumn{11}{|c|}{ Item } & & \multirow{2}{*}{ EQ } & \multirow{2}{*}{ EN } \\
\hline & I1 & $\mathrm{I} 2$ & I3 & I4 & I5 & I6 & I7 & I8 & I9 & $\mathrm{I} 10$ & I11 & $\mathrm{I} 12$ & & \\
\hline E1 & 21 & 13 & 9 & 17 & 10 & 0 & 19 & 12 & 17 & 0 & 0 & 14 & 132 & 9 \\
\hline E2 & 33 & 0 & 17 & 39 & 24 & 58 & 21 & 23 & 8 & 32 & 27 & 21 & 303 & 11 \\
\hline E3 & 19 & 5 & 22 & 0 & 11 & 41 & 25 & 0 & 16 & 54 & 49 & 6 & 248 & 10 \\
\hline $\mathrm{E} 4$ & 0 & 7 & 10 & 15 & 8 & 21 & 12 & 14 & 9 & 20 & 0 & 11 & 127 & 10 \\
\hline E5 & 352 & 11 & 43 & 12 & 23 & 249 & 17 & 12 & 12 & 18 & 72 & 10 & 831 & 12 \\
\hline E6 & 12 & 0 & 22 & 6 & 9 & 32 & 31 & 6 & 17 & 33 & 41 & 5 & 214 & 11 \\
\hline E7 & 307 & 13 & 20 & 11 & 32 & 278 & 42 & 11 & 15 & 29 & 137 & 12 & 907 & 12 \\
\hline E8 & 14 & 9 & 8 & 7 & 0 & 16 & 10 & 9 & 11 & 10 & 11 & 0 & 105 & 10 \\
\hline E9 & 33 & 5 & 31 & 0 & 7 & 42 & 35 & 12 & 17 & 19 & 0 & 7 & 208 & 10 \\
\hline E10 & 27 & 0 & 0 & 11 & 14 & 23 & 16 & 13 & 0 & 15 & 17 & 10 & 146 & 9 \\
\hline E11 & 18 & 6 & 45 & 6 & 9 & 67 & 47 & 10 & 31 & 34 & 0 & 6 & 279 & 11 \\
\hline E12 & 16 & 8 & 12 & 0 & 8 & 20 & 14 & 0 & 13 & 26 & 17 & 0 & 134 & 9 \\
\hline E13 & 22 & 0 & 7 & 13 & 22 & 18 & 18 & 15 & 0 & 14 & 0 & 12 & 141 & 10 \\
\hline E14 & 31 & 5 & 18 & 5 & 0 & 49 & 21 & 13 & 17 & 22 & 29 & 8 & 218 & 11 \\
\hline E15 & 299 & 8 & 6 & 11 & 19 & 215 & 7 & 6 & 9 & 70 & 69 & 10 & 729 & 12 \\
\hline E16 & 17 & 0 & 15 & 10 & 11 & 31 & 13 & 10 & 0 & 16 & 18 & 9 & 150 & 10 \\
\hline E17 & 234 & 11 & 0 & 8 & 23 & 222 & 12 & 9 & 14 & 21 & 30 & 8 & 592 & 11 \\
\hline E18 & 19 & 0 & 13 & 0 & 10 & 13 & 0 & 9 & 10 & 17 & 15 & 7 & 113 & 9 \\
\hline E19 & 21 & 6 & 15 & 10 & 12 & 17 & 0 & 10 & 13 & 15 & 0 & 10 & 129 & 10 \\
\hline E20 & 39 & 0 & 22 & 17 & 19 & 35 & 29 & 19 & 0 & 33 & 0 & 0 & 213 & 8 \\
\hline IQ & 1534 & 107 & 335 & 198 & 271 & 1447 & 389 & 213 & 229 & 498 & 532 & 166 & 5919 & \\
\hline IK & 19 & 13 & 18 & 16 & 18 & 19 & 18 & 18 & 17 & 19 & 13 & 17 & & 205 \\
\hline
\end{tabular}




\section{A. EQ Analysis and Application}

Each entry's shipment quantity are arranged in descending order, and sorted are numbered $1,2, \ldots 20$. EQ analysis table is shown in Table II.

TABLE II. EQ DISTRIBUTION TABLE

\begin{tabular}{|c|c|c|c|}
\hline Entry number & E & Q & $\begin{array}{c}\text { Entry cumulative } \\
\text { shipments }\end{array}$ \\
\hline 1 & E7 & 907 & 907 \\
\hline 2 & E5 & 831 & 1738 \\
\hline 3 & E15 & 729 & 2467 \\
\hline 4 & E17 & 592 & 3059 \\
\hline 5 & E2 & 303 & 3362 \\
\hline 6 & E11 & 279 & 3641 \\
\hline 7 & E3 & 248 & 3889 \\
\hline 8 & E14 & 218 & 4107 \\
\hline 9 & E6 & 214 & 4321 \\
\hline 10 & E20 & 213 & 4534 \\
\hline 11 & E9 & 208 & 4742 \\
\hline 12 & E16 & 150 & 4892 \\
\hline 13 & E10 & 146 & 5038 \\
\hline 14 & E13 & 141 & 5179 \\
\hline 15 & E12 & 134 & 5313 \\
\hline 16 & E1 & 132 & 5445 \\
\hline 17 & E19 & 129 & 5574 \\
\hline 18 & E4 & 127 & 5701 \\
\hline 19 & E18 & 113 & 5814 \\
\hline 20 & E8 & 105 & 5919 \\
\hline Ass & & \\
\hline $7 n g$ & 16 & $0 f 5$ & 0 \\
\hline
\end{tabular}

Assuming that the ratio of 5:3:2 of orders' shipments and cumulative shipments are ABC classification. Since shipments have been in descending order, then the top $50 \%$ of shipments and cumulative shipments on behalf of key orders which orders smaller and shipments more, which are classified into Class A; the final $20 \%$ of shipments and cumulative shipments on behalf of nonpriority orders which orders more and shipments smaller, and these orders are classified into Class $C$; the rest are classified into Class B. After determining the ratio of ABC classification, EQ analysis also needs to separate the A, B, $\mathrm{C}$ class orders from the graph. It is necessary to determine the A, B classification critical point, B, C classification critical point and establish EQ-ABC classification reference data table as shown in Table III [8-9].

TABLE III. EQ-ABC CLASSIFICATION REFERENCE DATA TABLE

\begin{tabular}{|c|c|c|c|}
\hline & & $\begin{array}{c}\text { A, B } \\
\text { classification } \\
\text { critical point }\end{array}$ & $\begin{array}{c}\text { B, C } \\
\text { classification } \\
\text { critical point }\end{array}$ \\
\hline \multirow{2}{*}{$\begin{array}{c}\text { Theoretical } \\
\text { classificatio } \\
\text { n value }\end{array}$} & $\begin{array}{c}\text { Percentage } \\
\text { classification value }\end{array}$ & $50 \%$ & $80 \%$ \\
\cline { 2 - 4 } & $\begin{array}{c}\text { Cumulative } \\
\text { shipments critical } \\
\text { point }\end{array}$ & 2959.5 & 4735.2 \\
\hline \multirow{2}{*}{$\begin{array}{c}\text { Actual } \\
\text { classificatio } \\
\text { n value }\end{array}$} & Number & 4 & 11 \\
\cline { 2 - 4 } & Shipments & 592 & 208 \\
\cline { 2 - 4 } & $\begin{array}{c}\text { Cumulative } \\
\text { shipments }\end{array}$ & 3059 & 4742 \\
\cline { 2 - 4 } & Error bars X value & 16 & 9 \\
\hline
\end{tabular}

Use EQ distribution table and EQ-ABC classification reference data table make EQ Plato as shown in Fig .2.

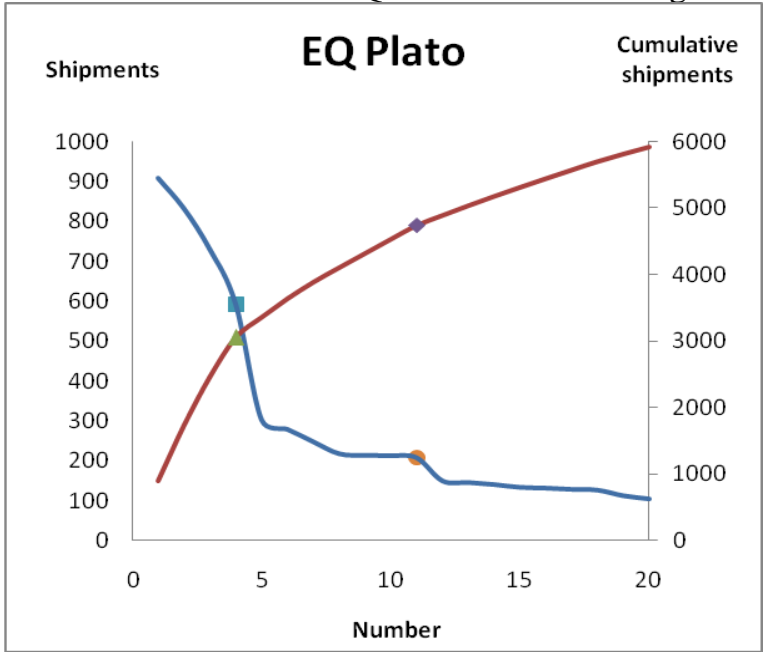

Figure 2. EQ Plato

From EQ distribution table and EQ Plato, it can be seen that: the book enterprise's order shipments distribution tends to polarize and orders can be classified by $\mathrm{ABC}$ classification. E7, E5, E15 and E17 are Class A orders, their orders accounted for $20.00 \%$ of total orders, shipments accounted for $51.68 \%$ of total shipments, should be used in batches picking; E2, E11, E3, E14, E6, E20 and E9 are Class B orders, their orders accounted for $35.00 \%$ of total orders, shipments accounted for $28.43 \%$ of total shipments, should be used in general picking; E16, E10, E13, E12, E1, E19, E4, E18 and E8 are Class C orders, their orders accounted for $45.00 \%$ of total orders, shipments accounted for $19.89 \%$ of total shipments, on the basis of artificial picking orders can be combined and use wave picking strategy.

\section{B. EN Analysis and Application}

The book enterprise's orders data shows that the total number of book item is 12. Statistics of the number of every order's shipments item can be drawn into EN distribution as shown in Fig.3.

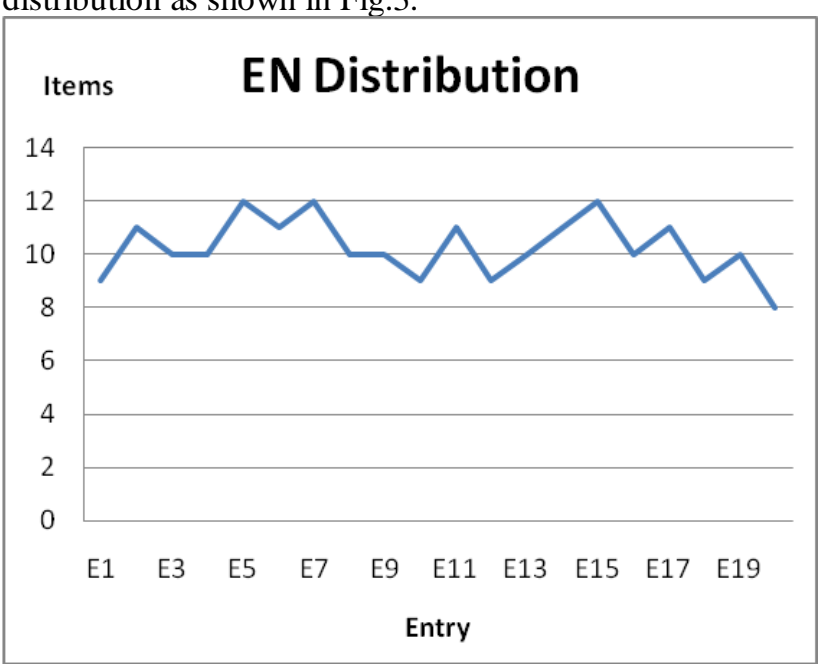

Figure 3. EN Distribution

According to EN distribution can be seen: The maximum number of commodity items is 12 , the minimum 
number of commodity items is 8 and the number of items in each order commodity hovering around 10. Because of the high repetition rate of orders commodity items, batch picking can be considered.

\section{IQ Analysis and Application}

Each item's shipment quantity are arranged in descending order, and sorted are numbered $1,2, \ldots 20$. IQ analysis table is shown in Table IV. Assuming that the ratio of 5:3:2 of orders' shipments and cumulative shipments are $\mathrm{ABC}$ classification and the establishment of IQ-ABC classification reference data table is shown in Table V.

TABLE IV. IQ DISTRIBUTION TABLE

\begin{tabular}{|c|c|c|c|}
\hline Number & I & Q & $\begin{array}{c}\text { Item cumulative } \\
\text { shipments }\end{array}$ \\
\hline 1 & I1 & 1534 & 1534 \\
\hline 2 & I6 & 1447 & 2981 \\
\hline 3 & I11 & 532 & 3513 \\
\hline 4 & I10 & 498 & 4011 \\
\hline 5 & I7 & 389 & 4400 \\
\hline 6 & I3 & 335 & 4735 \\
\hline 7 & I5 & 271 & 5006 \\
\hline 8 & I9 & 229 & 5235 \\
\hline 9 & I8 & 213 & 5448 \\
\hline 10 & I4 & 198 & 5646 \\
\hline 11 & I12 & 166 & 5812 \\
\hline 12 & I2 & 107 & 5919 \\
\hline
\end{tabular}

TABLE V.

IQ-ABC CLASSIFICATION REFERENCE DATA TABLE

\begin{tabular}{|c|c|c|c|}
\hline & & $\begin{array}{c}\text { A, B } \\
\text { classification } \\
\text { critical point }\end{array}$ & $\begin{array}{c}\text { B, C } \\
\text { classification } \\
\text { critical point }\end{array}$ \\
\hline \multirow{2}{*}{$\begin{array}{c}\text { Theoretical } \\
\text { classification } \\
\text { value }\end{array}$} & $\begin{array}{c}\text { percentage } \\
\text { classification } \\
\text { value }\end{array}$ & $50 \%$ & $80 \%$ \\
\cline { 2 - 4 } & $\begin{array}{c}\text { Cumulative } \\
\text { shipments critical } \\
\text { point }\end{array}$ & 2959.5 & 4735.2 \\
\hline \multirow{2}{*}{$\begin{array}{c}\text { Actual } \\
\text { classification } \\
\text { value }\end{array}$} & number & 2 & 7 \\
\cline { 2 - 4 } & Shipments & 1447 & 271 \\
\cline { 2 - 4 } & cumulative & 2981 & 5006 \\
\cline { 2 - 4 } & Ehipments & 10 & 5 \\
\hline
\end{tabular}

Use IQ distribution table and IQ-ABC classification reference data table make IQ Plato as shown in Fig .4.

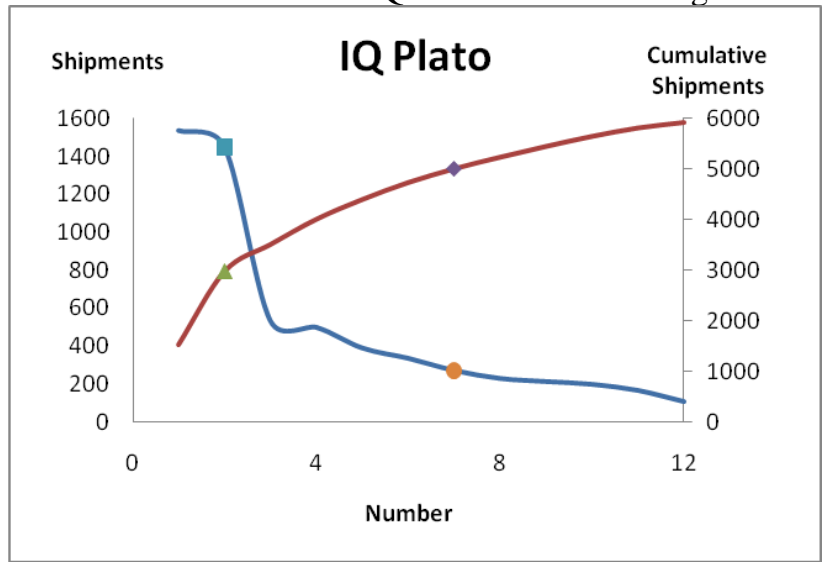

Figure 4. IQ Plato
From IQ distribution table and IQ Plato, it can be seen that: the book enterprise's item shipments distribution tends to polarize and items can be classified by $\mathrm{ABC}$ classification. I1 and I6 are Class A items, their items accounted for $16.66 \%$ of total orders, shipments accounted for $50.36 \%$ of total shipments, should be ensured adequate supply. In addition, Class A can be placed in easy picking and exit from the position near or easy job to shorten the distance picking. I11, I10, I7, I3 and I5 are Class B items, their items accounted for $41.76 \%$ of total orders, shipments accounted for $34.22 \%$ of total shipments. I9, I8, I4, I12 and I 2 are Class $C$ items, their items accounted for $41.76 \%$ of total items, and shipments accounted for $15.42 \%$ of total shipments. Class $\mathrm{C}$ should be placed on top of the storage area and placed in a position far from the exit.

\section{IK Analysis and Application}

According to order data for book enterprise can be seen: The highest number of each item's shipping times is 19 , the lowest number of each item's shipping times is 13, the average number of each item's shipping times is 17 and the gap of every item's shipping times is not large. IK analysis can also be combined with IQ analysis to calculate the average of single product single shipment (Table VI) to classify and determine the storage arrangements and equipment use [10].

TABLE VI. THE AVERAGE OF SINGLE PRODUCT SINGLE SHIPMENT

\begin{tabular}{|c|c|c|c|}
\hline & IQ & IK & IQ/IK \\
\hline I1 & 1534 & 19 & 80.7 \\
\hline I2 & 107 & 13 & 8.2 \\
\hline I3 & 335 & 18 & 18.6 \\
\hline I4 & 198 & 16 & 12.4 \\
\hline I5 & 271 & 18 & 15.1 \\
\hline I6 & 1447 & 19 & 76.2 \\
\hline I7 & 389 & 18 & 21.6 \\
\hline I8 & 213 & 18 & 11.8 \\
\hline I9 & 229 & 17 & 13.5 \\
\hline I10 & 498 & 19 & 26.2 \\
\hline I11 & 532 & 13 & 40.9 \\
\hline I12 & 166 & 17 & 9.8 \\
\hline
\end{tabular}

From Table VI, it can be seen that: I1 and I6's total shipments and average single shipments are large, planning should be assigned a fixed storage spaces and to ensure a high level of inventory. I11's total shipments and average single shipments are relatively large, so that the classification is not obvious sense. I2, I3, I4, I5, I7, I8, I9, I10 and I12's total shipments and average single shipments are small. These items should be assigned elastic storage spaces and cargo space size should be appropriate to adjust, picking area and storage areas can be combined to reduce excess inventory and inventory levels.

\section{CONCLUSION}

EIQ analysis departures from the order data, according to the supply chain downstream customers' demand characteristics, combines with the ABC classification, EIQ analysis results are obtained. According EIQ analysis, it can be understood that the order features, provide data support for the warehouse layout and order picking strategies. In addition, through EIQ analysis, companies can also get a lot of useful information, including changes 
in market demand trends, logistics equipment selection and logistics system planning[11].

\section{REFERENCES}

[1] JI San-you, YU Jing. Application of EIQ analysis in the book logistics center planning [J]. Southeast University, 2007,37 : 333336.

[2] ZHANG Han-yue. Research on the picking strategy based on EIQ analysis [J] China Logistics and Purchasing, 2010, (1):68-69.
[3] JI San-you, Yang Tao. Application of EIQ_ABC analysis in the planning of steel logistics center $[\mathrm{J}]$. Wuhan University of Technology, 2012, 34(1) : 46-48.

[4] XING Wei-ping.EIQ analysis based on Excel [J]. China management information, 2010, 14(13):68-70.

[5] XIE Ming-guo. Application of the picking strategy based on EIQ analysis [J]. Logistics Technology, 2011,2:75-76.

[6] LI Qiang. Application of EIQ analysis to storage management [J]. Modern Commercial Industry, 2011,(11):46-47.

[7] WU Jiang, PAN Xiao-yong, LIU Da-wei, LIU Yong-liang, LAI Dong.EResearch on the application of EIQ in warehouse management [J]. Henan Science, 2013, 31(12) : 2302-2305. 